\title{
Evaluating Sustainability of Architectural Designs Using Building Information Modeling
}

\author{
T.H. Nguyen ${ }^{1, *}$, T. Shehab ${ }^{1}$ and Z. Gao ${ }^{2}$ \\ ${ }^{I}$ Department of Civil Engineering \& Construction Engineering Management, California State University Long Beach, \\ USA \\ ${ }^{2}$ Department of Construction Management \& Engineering, North Dakota State University, USA
}

\begin{abstract}
BIM (Building Information Modeling) has been recently implemented by many Architecture, Engineering, and Construction firms due to its productivity gains and long term benefits. This paper presents the development and implementation of a sustainability assessment framework for an architectural design using BIM technology in extracting data from the digital building model needed for determining the level of sustainability. The sustainability assessment is based on the LEED (Leadership in Energy and Environmental Design) Green Building Rating System, a widely accepted national standards for sustainable building design in the United States. The architectural design of a hotel project is used as a case study to verify the applicability of the framework.
\end{abstract}

Keywords: Sustainability, Architectural designs, BIM, LEED.

\section{INTRODUCTION}

The environmental impact of constructed facilities has become a great concern among professionals in the construction industry. According to [1], in the United States, commercial and residential buildings consume close to $40 \%$ of our total energy, $70 \%$ of our electricity, $40 \%$ of our raw materials, and $12 \%$ of fresh water supplies. They account for $30 \%$ of greenhouse gas emissions and generate 136 tons of construction and demolition waste (approximately $2.8 \mathrm{lbs} /$ person/day). Recently, sustainable design, a growing field within architectural design, has been emerged in the construction industry as the practice of designing, constructing, and operating facilities in such a manner that their environmental impact can be minimized. Facilities designed with sustainable solutions usually save more money on energy and water bills since sustainable design is aimed at producing green buildings that are designed to be 'environmentally responsible, profitable and healthy places to live and work' $[2]$.

As with traditional building design methods, sustainability assessment based on the graphic representations of conventional CAD (Computer-Aided Design) requires a great deal of human intervention and interpretation, which makes the assessment costly and/or time-consuming. In the last 20 years, information technology has revolutionized the building design and the adoption of advanced CAD modeling in building design has made the final products more efficient and less costly since it provides the data needed for building performance analysis and evaluation (e.g. sustainability assessment) as design on the project proceeds. This approach to building design is so different from that using conventional CAD software which has been named as BIM

*Address correspondence to this author at the Department of Civil Engineering \& Construction Engineering Management, California State University Long Beach, USA;

E-mails: thnguyen@csulb.edu,hungnguyen84@hotmail.com
(Building Information Modeling). BIM has been implemented by some AEC (Architecture, Engineering, and Construction) firms due to its productivity gains and long term benefits. This paper is aimed at developing a sustainability assessment framework for an architectural design, which makes use of BIM technology in extracting data from the digital building model needed for supporting the assessment. This paper is organized as follows: first, standards for sustainability assessment is provided; second, sustainability assessment methods are presented; third, the introduction to BIM and how to use BIM to restore sustainabikity indicators are discussed; fourth, the framework for sustainability assessment of a building design is described; next, the implementation of the framework into a computer platform (e.g. Autodesk Revit Architecture) and a case study are discussed; finally, the conclusion of the research project is summarized.

\section{STANDARDS FOR SUSTAINABILITY ASSESSMENT}

In the United States, the widely accepted national standards for sustainable building design are known as the LEED (Leadership in Energy and Environmental Design) Green Building Rating System. It has been developed by a national sustainable design organization, named the USGBC (U.S. Green Building Council), which was formed in 1993 by a group of leaders from the North American Building Industry. Basically, the LEED rating system awards points for satisfying specified green building criteria into five major categories: sustainable sites, water efficiency, energy and atmosphere, materials and resources, and indoor environmental quality; and sustainability of a project is rated by accumulating scores (100 points maximum) from these five major categories [2]. Table 1 presents the five categories/subcategories of LEED 2009 for new construction and major renovations project and their maximum possible points. The categories that are rated as "Required" in Table $\mathbf{1}$ must be included in the project and will not be given any points. 
Table 1. Leed 2009 for New Construction and Major Renovations Project Checklist

\begin{tabular}{|c|c|c|}
\hline Prerequisite 1 & Construction Activity Pollution Prevention & $\frac{26 \text { Possible Points }}{\text { Required }}$ \\
\hline Credit 2 & Development Density and Community Connectivity & 5 \\
\hline Credit 3 & Brownfield Redevelopment & 1 \\
\hline Credit 4.2 & Alternative Transportation-Bicycle Storage and Changing Rooms & 1 \\
\hline Credit 4.3 & Alternative Transportation-Low-Emitting and Fuel-Efficient Vehicles & 3 \\
\hline Credit 4.4 & Alternative Transportation—Parking Capacity & 2 \\
\hline Credit 5.1 & Site Development—Protect or Restore Habitat & 1 \\
\hline Credit 7.1 & Heat Island Effect—Non roof & 1 \\
\hline Credit 7.2 & Heat Island Effect-Roof & 1 \\
\hline Credit 8 & Light Pollution Reduction & 1 \\
\hline \multicolumn{2}{|l|}{ Water Efficiency } & 10 Possible Points \\
\hline Prerequisite 1 & Water Use Reduction & Required \\
\hline Credit 1 & Water Efficient Landscaping & $2-4$ \\
\hline Credit 2 & Innovative Wastewater Technologies & 2 \\
\hline Credit 3 & Water Use Reduction & $2-4$ \\
\hline Credit 2 & On-site Renewable Energy & $1-7$ \\
\hline Credit 3 & Enhanced Commissioning & 2 \\
\hline Credit 4 & Enhanced Refrigerant Management & 2 \\
\hline Credit 5 & Measurement and Verification & 3 \\
\hline Credit 6 & Green Power & 2 \\
\hline \multicolumn{2}{|c|}{ Materials and Resources } & 14 Possible Points \\
\hline Prerequisite 1 & Storage and Collection of Recyclables & Required \\
\hline Credit 1.1 & Building Reuse-Maintain Existing Walls, Floors and Roof & $1-3$ \\
\hline Credit 1.2 & Building Reuse-Maintain Existing Interior Nonstructural Elements & 1 \\
\hline Credit 2 & Construction Waste Management & $1-2$ \\
\hline Credit 3 & Materials Reuse & $1-2$ \\
\hline Credit 4 & Recycled Content & $1-2$ \\
\hline Credit 5 & Regional Materials & $1-2$ \\
\hline Credit 6 & Rapidly Renewable Materials & 1 \\
\hline Credit 7 & Certified Wood & 1 \\
\hline
\end{tabular}


Table 1. Cont...

\begin{tabular}{|c|c|c|}
\hline \multicolumn{2}{|c|}{ Indoor Environmental Quality } & \multirow{2}{*}{$\begin{array}{r}15 \text { Possible Points } \\
\text { Required }\end{array}$} \\
\hline Prerequisite 1 & Minimum Indoor Air Quality Performance & \\
\hline Prerequisite 2 & Environmental Tobacco Smoke (ETS) Control & Required \\
\hline Credit 1 & Outdoor Air Delivery Monitoring & 1 \\
\hline Credit 2 & Increased Ventilation & 1 \\
\hline Credit 3.1 & Construction Indoor Air Quality Management Plan—During Construction & 1 \\
\hline Credit 3.2 & Construction Indoor Air Quality Management Plan—Before Occupancy & 1 \\
\hline Credit 4.1 & Low-Emitting Materials_-Adhesives and Sealants & 1 \\
\hline Credit 4.2 & Low-Emitting Materials_-Paints and Coatings & 1 \\
\hline Credit 4.3 & Low-Emitting Materials—Flooring Systems & 1 \\
\hline Credit 4.4 & Low-Emitting Materials-Composite Wood and Agrifiber Products & 1 \\
\hline Credit 5 & Indoor Chemical and Pollutant Source Control & 1 \\
\hline Credit 6.1 & Controllability of Systems - Lighting & 1 \\
\hline Credit 6.2 & Controllability of Systems-Thermal Comfort 1 & \\
\hline Credit 7.1 & Thermal Comfort—Design 1 & \\
\hline Credit 7.2 & Thermal Comfort-Verification 1 & \\
\hline Credit 8.1 & Daylight and Views-Daylight 1 & \\
\hline Credit 8.2 & Daylight and Views-Views 1 & \\
\hline \multicolumn{2}{|c|}{ Innovation in Design } & 6 Possible Points \\
\hline Credit 1 & Innovation in Design & $1-5$ \\
\hline Credit 2 & LEED Accredited Professional & 1 \\
\hline Regional Priority & & 4 Possible Points \\
\hline Credit 1 & Regional Priority & $1-4$ \\
\hline
\end{tabular}

The LEED ratings are classified as Certified, Silver, Gold, and Platinum; which require, for new construction and major renovations project, in total 40-49 points, 50-59 points, $60-79$ points, and 80 or above, respectively. Additionally, there are three types of LEED points: Type 1 (Little or no cost premium), Type 2 (Cost, but short-term return on investment), and Type 3 (Cost, with long-term or no return on investment).

\section{SUSTAINABILITY ASSESSMENT METHODS}

There are several sustainability assessment techniques for building development. As an example, BREEAM (Building Research Establishment Environmental Assessment Method) is an environmental assessment method for buildings, which has been mostly used in Europe. It sets the standard for best practice in sustainable design and has become the de facto measure used to describe a building's environmental performance [3]. HK-BEAM (Hong Kong Building Environmental Assessment Method) is another sustainability method that makes references to Hong Kong building energy codes for environmental assessment [4]. In United States, the most popular method is the LEED (Leadership in Energy and Environmental Design) method. The LEED method is known to be an effective method for measuring sustainability level of housing and building applications.

In addition, sustainability of a building project can be measured and evaluated by using qualitative and/or quantitative techniques. While qualitative methods use comparable measurements such as impact on ecological value of the site and impact on local environment; quantitative techniques focus on numerical values of annual energy use, water consumption, greenhouse gas emissions, air pollution, acidification, and low level ozone production.

Qualitative criteria play a major role in determining how buildings perform with respect to sustainability level. Qualitative criteria are usually measured and evaluated based on opinions instead of facts and it requires a great deal of time and effort from an unbiased third party to be successful. Even after a massive effort of data collection and input, the final rating can be skewed by a subjective judgement [5]. Moreover, there are always major differences in judgments among various stakeholders, including architects, engineers and other professionals [5]. When multi criteria involve the sustainability assessment, AHP (Analytic Hierarchy Process) is a suitable tool for the assessment since it supports comparison of different options. The AHP was developed by [6] and has been applied in construction decision making processes [7] and [8], in which the decision factors are subjective and qualitative. AHP is effective in supporting the assessment of and decision making on complex sustainability issues because they can integrate a diversity of criteria in a multidimensional guise and they can be adapted to a large variety of contexts.

Quantitative criteria can be measured readily based on the total consumption level of sustainability and points awarded accordingly. For instance, in LEED, 1-19 credit points are awarded if the building energy performance is properly optimized. In BREEAM, 8 credit points are given for $\mathrm{CO}_{2}$ emissions between 160 and $140 \mathrm{~kg} / \mathrm{m}^{2}$ per year and 
more points are awarded if $\mathrm{CO}_{2}$ emissions are further reduced [3]. Thus, it is obvious that existing quantitative techniques have value in practice; however, the assessment factors can hide the detail of cultural, epistemological, economic and technical influences. One example is the window area, which is linked to building performance in terms of energy use, occupant satisfaction and the variable used to measure passive solar gain in building assessment. Often this is simply measured by the window area, but this leaves many influencing factors unquestioned-window orientation, shading by other buildings and depth of surround [5]. In other words, assessing quantitative criteria in theory seems straightforward, but in reality will involve many other subjective factors. Consequently, sustainability assessments require communication and interaction between the stakeholders in building design, construction and operation.

\section{BIM (BUILDING INFORMATION MODELING)}

Building information modeling is an innovative new approach to building design, engineering, and construction management that was introduced by Autodesk in 2002. According to American Institute of Architects, BIM is defined as a model-based technology linked with a database of project information, which can be accessed and shared among different project participants [9]. Information embedded in BIM objects is available throughout the entire design and construction process. Data can be viewed as a $3 \mathrm{D}$ (three dimensional) model or traditional 2D (two dimensional) construction drawings, and can be integrated with other programs for construction estimating, scheduling, and project management. The most productive function of a BIM is that all the updates needed in construction documentation including schedules and estimates can be done by a single change of the BIM.

While many CAD (Computer-Aided Design) software (e.g. Revit Building by Autodesk, Inc., Triforma by Bentley, Inc., and ArchiCAD by Graphisoft, Inc.) provide BIM solutions, most of digital building models do not contain sufficient information for evaluation of building performance regarding sustainability. Among these CAD software, Autodesk Revit Building was built using parametric building modeling technology, in which buildings are represented as an integrated database containing both graphical and nongraphical information [10]. In effect, beyond graphically depicting the design, BIM models in Autodesk Revit Building contains parameters needed for supporting sustainable design that can be automatically captured during the design process. In Revit, each building or design component is associated with predefined parameters which are grouped into two categories: type parameters and instance parameters. The type parameters control all elements of the same type whereas the instance parameters control selected or created instances. The type and instance parameters are further categorized into different groups. Each parameter can be stored in different formats such as: text, integer, number, length, area, volume, angle, URL, material, and yes/no. In addition, new parameters such as sustainability indicators can be created and stored as project parameters which can be used to determine the magnitude of sustainability of a building project. The following section discusses the integration of sustainability indicators in BIM models.

\section{USING BIM TO STORE SUSTAINABILITY INDICA- TORS}

Sustainability indicators represent a generic expression for quantitative or qualitative sustainability variables [11]. For housing and building applications, according to the LEED assessment system, these sustainability variables are grouped into five major categories: sustainable sites, water efficiency, energy and atmosphere, materials and resources, and indoor environmental quality. Many sub-indicators can be organized under a main indicator. For example, under the category "Water Efficiency", the sub-indicators are Water Efficiency Landscaping, Innovative Wastewater Technologies, and Water Use Reduction (see Table 1). The number of indicators and their coverage depends on the complexity of the sustainability assessment and the project itself. These sustainability indicators (e.g. LEED criteria) can be created and stored as parameters in BIM software. For instance, in Revit Architecture 2010, new parameters such as sustainability indicators can be created as project parameters or shared parameters (see Fig. 1), in which only the shared parameters can be exported to databases. These are shared by other families and projects, whereas project parameters are not exported to the databases. The newly created parameters on this project focused on information needed for the sustainability assessment. Fig. (2) shows examples of sustainability indicators (LEED criteria for Energy and Atmosphere) that are created as new project parameters under the project property 'Green Building Properties' in Revit.

\section{THE SUSTAINABILITY ASSESSMENT FRAME- WORK}

The proposed sustainability assessment framework is developed using the formality of a standard process and information model, i.e. IDEF0 (Integrated Definition for Function Modeling) [12]. The IDEF0 model indicates major activities and the input, control, output, and mechanisms associated with each major activity. In the context of sustainability assessment of a building design project, inputs are the typical building components analyzed and evaluated by a process. Outputs are the magnitude of sustainability resulted from the transformations/assessment of the inputs by the process. Controls are the standards, criteria, guidelines, etc., that guide the assessment process (e.g. LEED criteria). Mechanisms are the assessment methods or techniques that accomplish the actions delineated within the process. Fig. (3) is an abstract view of IDEF0 notation for the sustainability assessment framework.

In general, the assessment process includes three major steps: first, the framework, by means of functions, identifies aspects and interests related to sustainability of project development and translates them into sustainability indicators. Then, these indicators are assessed by using different techniques (qualitative or quantitative methods) together with the predefined assessment standards (e.g. LEED criteria). Finally, the level of sustainability of the building design is reported.

\section{IMPLEMENTATION AND CASE STUDY}

The sustainability assessment framework was implemented into Autodesk Revit 2010, a BIM software commonly used in the Architecture, Engineering, and Construction industry. Also, the architectural design of a hotel project 


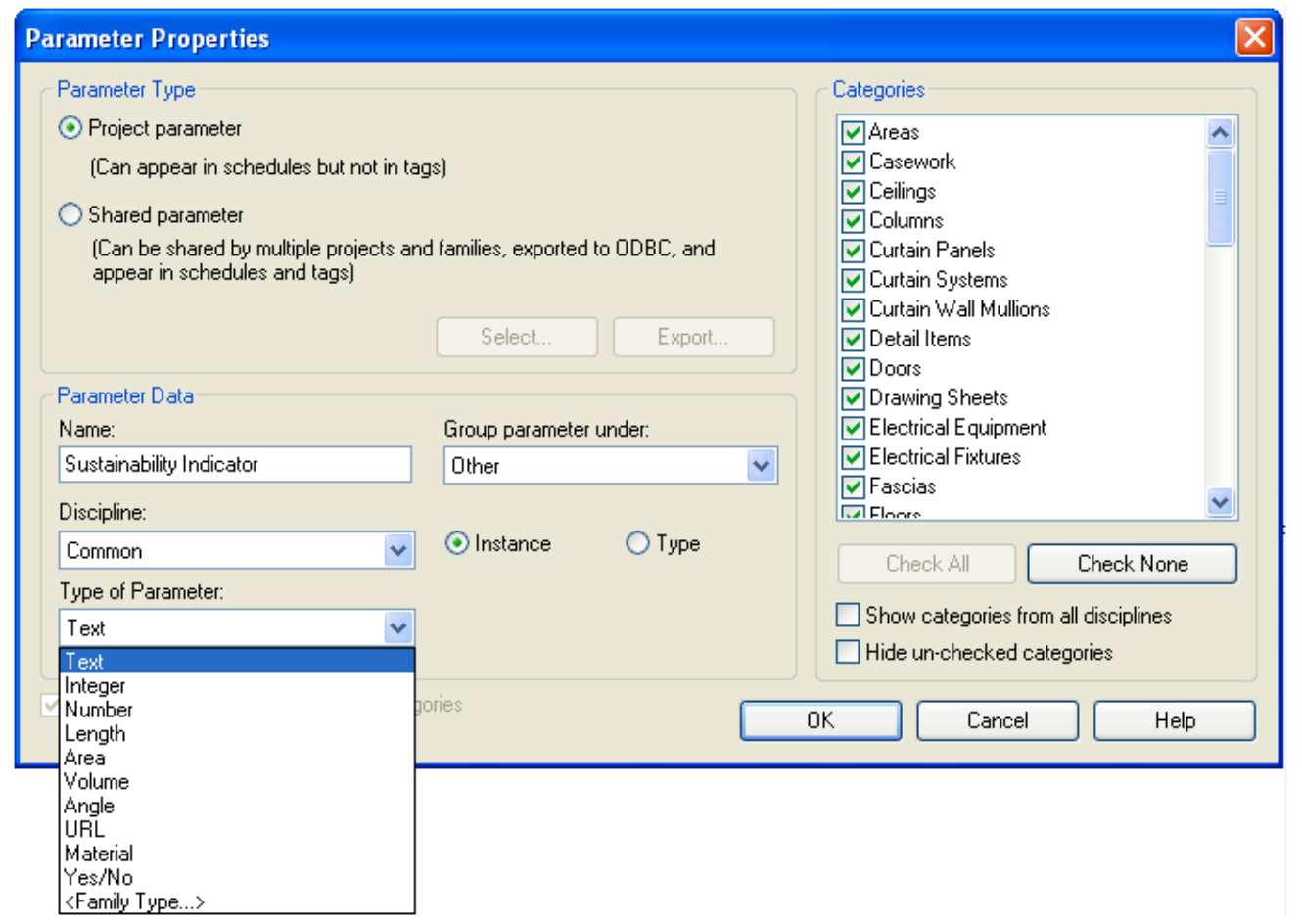

Fig. (1). Building information stored as parameters in REVIT software.

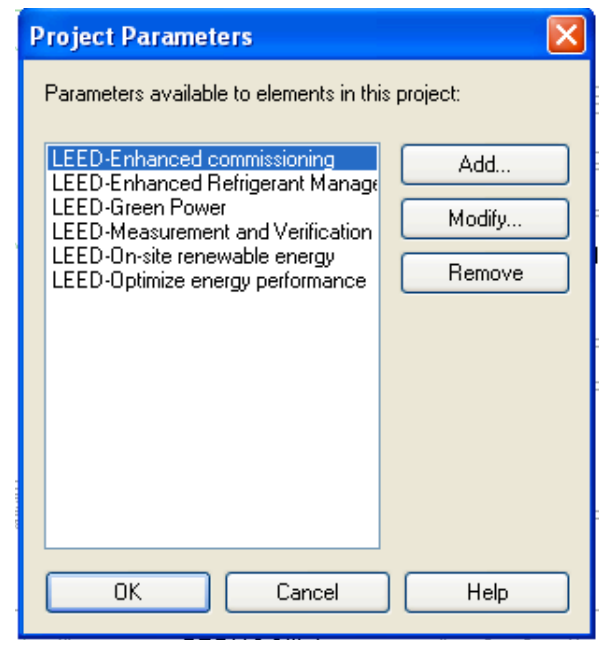

Fig. (2). LEED criteria created as new project parameters in REVIT software.

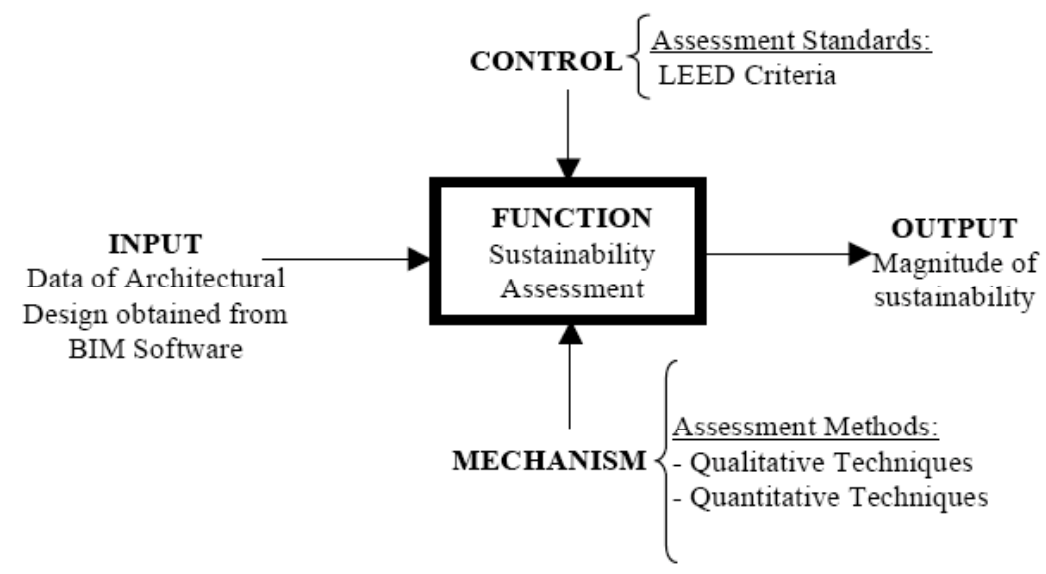

Fig. (3). The sustainability assessment framework. 
was used as a case study to verify the applicability of the sustainability assessment framework. The hotel project (see Fig. 4) consists of sixteen floors located on a footprint area of $444 \mathrm{~m}^{2}\left(4,780 \mathrm{ft}^{2}\right)$. Reinforced concrete was the main construction material for the project structural system. The hotel façade is covered with a large curtain wall system in order to maximize the daylight utilization. Fig. (4) shows the information about the green building properties of a basic wall of the case study in Revit that can be extracted for calculating the maximum possible points for LEED ratings (see Fig. $\mathbf{5}$ as an example). In order to use the Revit BIM as a sustainability assessment tool, it is necessary to program some additional features into the software [13]. The additional features are needed to display a static graphical model showing the building components together with their own properties including both graphical and non-graphical information. The static BIM model used VB.Net to create the conditional query. Executing conditional query is not readily available in Revit but it is feasible through Revit API (Application Programming Interface) [13]. This feature was customized by developing an interface between Revit, and MS Access through Revit APIs using Visual Basic V. 6.0. This query facilitates the retrieval of information necessary for sustainability assessment; i.e. computing the maximum possible points for LEED ratings. Fig. (6) shows a typical interface screen for executing a sustainability assessment query and providing the final report with a LEED rating: 'Platinum' as the total maximum possible points are greater than 80 .

\section{CONCLUSION}

BIM (Building Information Modeling) has been implemented by a number of Architecture, Engineering, and Construction firms due to its productivity gains and long term benefits. A sustainability assessment framework for an architectural design based on the formality of a standard process and information model, i.e. IDEF0 (Integrated Definition for Function Modeling) is described in this paper. The framework makes use of BIM technology in extracting data from the digital building model needed for supporting the sustainability assessment. The architectural design of a hotel project is used as a case study to verify the applicability of the framework. The sustainability assessment of the case study is based on the LEED (Leadership in Energy and Environmental Design) Green Building Rating System, a widely accepted national standards for sustainable building design in the United States. In general, the LEED criteria are first created in the hotel project; i.e. BIM model in Revit, as green building properties/parameters or sustainability indicators. These sustainability indicators are then extracted to compute the maximum possible points for LEED ratings by using different techniques (qualitative or quantitative methods) together with the predefined assessment standards (e.g. LEED criteria). Finally, the level of sustainability of the building design is reported.

In the future research, the following works should be conducted: exploring all the factors related to the construction process through the project life cycle, addressing the

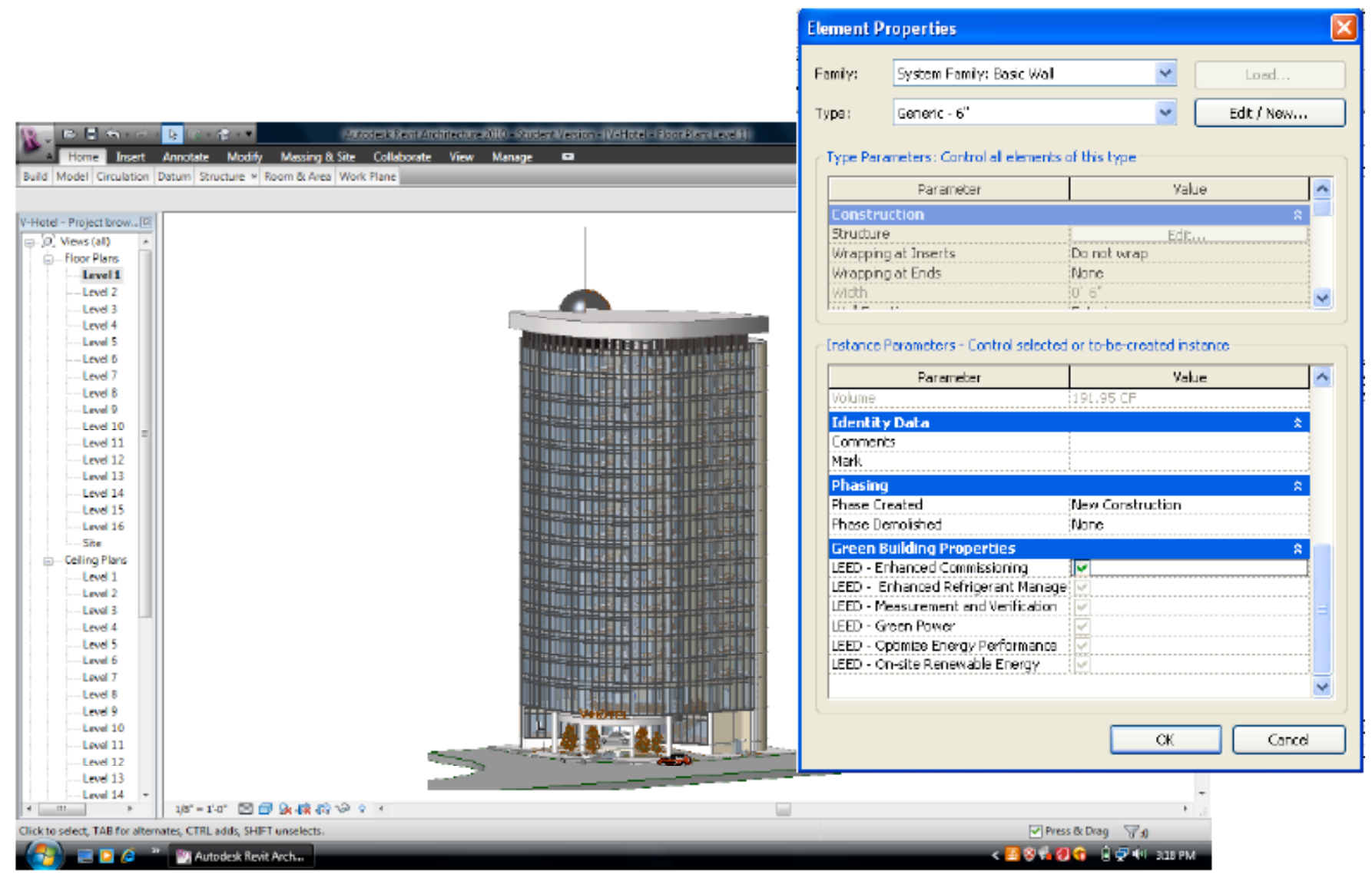

Fig. (4). Green building properties in a case study project. 


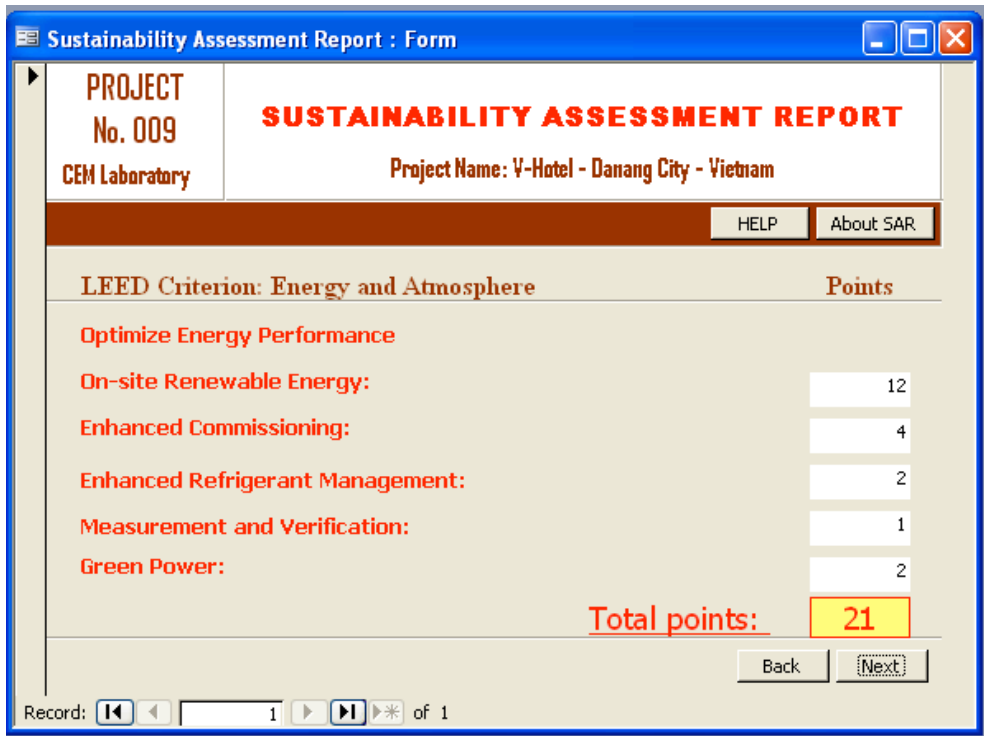

Fig. (5). Sustainability assessment in a case study.

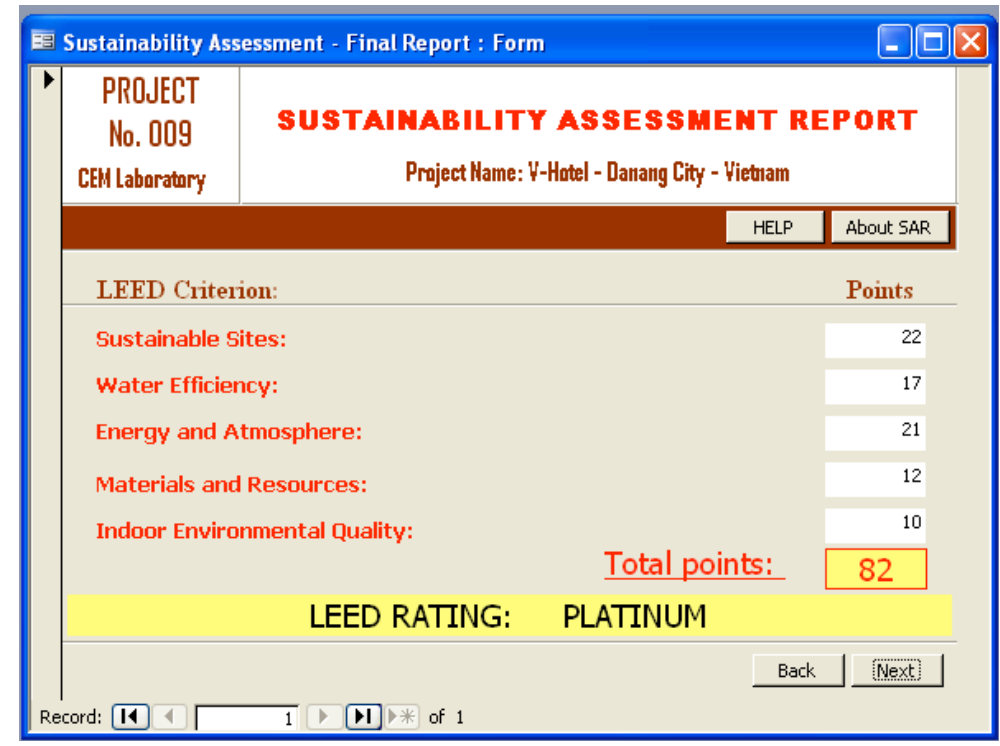

Fig. (6). Final report on sustainability assessment in a case study.

complicated interrelationships between sustainability aspects, and developing a standard generic framework for sustainability assessment using BIM technology that results in a persuasive and plausible process.

\section{REFERENCES}

[1] "Energy Efficiency and Renewable Energy Network (EREN)", Center of Excellence for Sustainable Development, U.S Department of Energy, 2003. Available at http://www.eere.energy.gov/

[2] "Leadership in Energy and Environmental Design (LEED)". United States Green Building Council (USGBC). Available from http:// www.usgbc.org/ShowFile.aspx?DocumentID=5546 [Accessed on 20 April, 2009].

[3] "BREEAM: The Environmental Assessment Method For Buildings Around The World". Available from http://www.breeam.org/index. jsp [Accessed on 25 June, 2009].

[4] "Hong Kong Building Environmental Assessment Method". Available from http://www.hk-beam.org.hk/general/home.php [Accessed on 30 June, 2009].
[5] H. AlWaer, M. Sibley and J. Lewis, "Different stakeholder perceptions of sustainability assessment". Architectural Science Review, March 01, 2008. Available from http://goliath.ecnext.com/coms2/gi 0199-7651446/Different-stakeholder-perceptions-of-sustainability. html [Accessed on 20 August, 2009].

[6] T. L. Saaty, The Analytic Hierarchy Process, McGraw-Hill: New York, 1980.

[7] Z. Mohamed, K. Nigem, A. Enshassi and B. M. Ayyub, "Strategic implementation of infrastructure priority projects: Case study in Palestine", Journal of Infrastructure Systems, vol. 8, no. 1, pp. 2$11,2002$.

[8] A. Shapira and M. Goldenberg, "AHP-based equipment selection model for construction projects", Journal of Construction Engineering and Management, vol. 131, no. 12, pp. 1263-1273, 2005.

[9] G. Lee, R. Sacks and C. M. Eastman, "Specifying parametric building object behavior (BOB) for a building information modeling system", Automation in Construction, vol.15, no. 6, pp. 758-776, 2006.

[10] T. Dzambazova, G. Demchak and E. Krygiel, Mastering Revit Architecture 2008. Wiley Publishing, Inc., Indianapolis, Indiana, 2008. 
[11] L. I. Harrington, G. Jones and M. Winograd, Measurements and Indicators of Sustainability. Report of a Consultancy Team, Centro International de Agricultura Tropical (CIAT), Cali: Colombia, 1993.

[12] "Integrated DEFinition Methods (IDEF0)". Available from http:// www.idef.com/idef0.html [Accessed on 20 June, 2009].
[13] J. D. Goedert and P. Meadati, "Integrating construction process documentation into building information modeling", Journal of Construction Engineering and Management, vol. 134, no. 7, pp. 509-516, 2008.

Received: September 02, 2009

Revised: December 19, 2009

Accepted: December 21, 2009

(C) Nguyen et al.; Licensee Bentham Open.

This is an open access article licensed under the terms of the Creative Commons Attribution Non-Commercial License (http://creativecommons.org/licenses/by-nc/3.0/) which permits unrestricted, non-commercial use, distribution and reproduction in any medium, provided the work is properly cited. 